\section{Floral Consumption Values for Consumer Groups with Different Purchase Choices for Flowers}

\author{
Li-Chun Huang ${ }^{1,3}$ and Tzu-Fang Yeh $^{2}$
}

ADDITIONAL INDEX WORDS. consumer value, purchase choice, market, flowers

Summary. Consumption values are theoretically believed to be the antecedents of the outcomes of consumer purchase choice. In the floral market, even though the context of floral consumption values has been explored, the relationship between floral consumption values and consumer's purchase choice regarding floral products remains unknown. This study, however, seeks to address this deficiency by attempting to evaluate the differences in floral consumption values across consumer groups that have different purchase choices for floral products. After collecting data from a consumer survey, which yielded 615 valid questionnaires, the statistical results indicated that consumers who revealed different purchase choices in regard to flowers had different floral consumption values. In descending order, showing care to others, emotion conditioning, and sensory hedonics were the floral consumption values most strongly recognized by the majority of the consumers. However, heavy users of flowers revealed different characteristics in that they more strongly recognized the psychological value of emotion conditioning rather than the social value of showing care to others. The main difference across consumer groups that had purchased flowers with different frequencies or that preferred to buy different types of flowers had to do with the epistemic value (i.e., curiosity fulfillment). The results of this study imply that consumers who have different choice behavior toward flowers possess different evaluative judgments in regard to floral products. Such differences not only lead consumers to have different purchase choices in regard to flowers, but are also very likely to influence the consumer's behavior in regard to information search and variety seeking in the floral market, which in turn, impacts the effectiveness of commercial communication in the floral market.

$\mathrm{H}$ ow to sell more flowers is always a concern of the practitioners in the floral market, therefore, understanding the driving forces that influence consumers' choices in regard to the purchases of flowers, such as to buy or not to buy, how much to buy, or what kinds of flowers to buy, will help florists in alleviating such concerns.

Sheth et al. (1991) proposed the theory of consumption values in explaining consumer choice behavior. In the conceptualization of their theory, there are five consumption values (i.e., functional value, social value, emotional value, epistemic value, and conditional value) that influence the consumer in his or her choice of whether to buy or not

We thank Neal E. De Vos, Charles R. Hall, and the anonymous reviewers for their review and insightful comments on an earlier version of this manuscript.

${ }^{1}$ Department of Bio-Industry Communication and Development, National Taiwan University, Taipei, 10617, Taiwan

${ }^{2}$ Da-Yeh University, Department of Human Resource and Public Relations, Da-Yeh University, Changhua, 51591, Taiwan

${ }^{3}$ Corresponding author. E-mail: lihuang@ntu.edu.tw. to buy, what types of product to buy, and what brands to buy. Consumption values illustrate the product values or benefits that consumers want to have from the products they buy, and different product categories may deliver different consumption values to consumers. For example, Sweeney and Soutar (2001) found that the consumption values for durable goods were set in terms of emotional value, social value, quality, and price. Oppenheim (2000) used consumption value factors to identify the market segment that was most likely to purchase flowers for in-home decoration, and found that for consumers who were more likely to purchase flowers for in-home decoration, they were more likely to do so for an emotional lift, to associate flowers with seasons, and to arrange unusual flowers.

The consumer's motivation to purchase and his or her preferences regarding the purchase of flowers also imply that consumers attach value to their desire to have flowers. According to the results of previous studies, consumers buy flowers to decorate their home/office, to celebrate a special event or moment, or simply for personal enjoyment (Kim et al., 1999). There are several factors that inhibit consumers from purchasing flowers, such as the low quality of products and the short vase life (Jowkar et al., 2007). Such inhibiting factors reflect the consumers' unwanted values for the floral products.

Matsuo (2008) observed that plants have a function of healing and pleasure for human beings because humans appreciate plants with all of their five senses and combine doing physical exercise with horticultural activities. Through their successful experiences of growing plants, people share their experiences and results with family members, neighbors, and friends, and therefore satisfy their need for belonging and self-esteem. Criley (2008) claimed that human appreciation for flowers is influenced by cultural differences. Because culture is usually aesthetically based, it influences how the beauty of ornamental plants is perceived. The study outcomes of Matsuo and Criley explore the psychological value, social value, and experiential value of flowers. Due to the values associated with flowers, flowers are intensively used in human life rituals (Goody, 1993).

Even though previous studies have explored the values of flowers from different dimensions, as described above, these findings were not systematically summarized. Therefore, Yeh and Huang (2009) cited the relevant findings from previous research and converted these findings into questionnaire statements that were used as tools to measure the consumption values that consumers have for the purchases of flowers. As a result, five consumption values were extracted for the floral products, including sensory hedonics, emotional conditioning, curiosity fulfillment, monetary worth, and showing care to others. Sensory hedonics refers to the sensory joy aroused by the floral products. Emotion conditioning refers to the psychological value of flowers in conditioning consumers' minds into a pleasant, calm, and peaceful status. Curiosity fulfillment refers to the value of flowers in satisfying the consumers' need to seek variety. Monetary worth refers to the value of the flowers in terms of physical performance, such as quality and longevity, which is evaluated in terms of the price consumers are prepared to pay. 
Different consumer groups may choose floral products in terms of different value aspects. For example, among the consumers in Japan, the younger generation tends to choose flowers based on first impressions, while the older generation tends to take the monetary value into consideration (Imanishi et al., 1992). In a market survey of Pennsylvania floral consumers, Behe and Wolnick (1991) found that the light users, medium users, and heavy users of flowers differ in regard to the intended use of the flowers purchased. For example, the heavy users tend to make many purchases of flowers for their personal enjoyment, while the light users of flowers tend to purchase flowers as gifts. Huang (2005) had a similar finding for the heavy users of flowers in that the heavy users of flowers have fewer negative attitudes toward flowers and tend to buy more flowers as daily essentials, as well as to buy more flowers as gifts.

Even though the context of the floral consumption values has been explored and theoretically it is said that consumption values are the driving force behind the outcomes of consumer choice (Sheth et al., 1991), the relationship between the floral consumption values and the consumer choices toward the purchases of flowers remains unknown. This study was conceived to address this deficiency. The objectives of this study were to evaluate floral consumption values across the consumer groups who had different purchase choices for flowers, such as the choice of whether to buy or not to buy flowers, how often to buy flowers, as well as what kinds of products to buy. This study evaluated the differences in the floral consumption values between the users and nonusers of flowers, the differences in floral consumption values among the light users, medium users, and heavy users of flowers, and the differences in floral consumption values among the consumer groups who prefer to buy different types of floral products, including cut flowers, potted plants, and other types of floral products.

\section{Methodology}

Questionnaire Design. A questionnaire was developed to serve as the instrument for data collection. The questions were composed based on the results of previous studies that implied the potential consumption values for the purchases of flowers. The conceptualizations of consumption value theory (Sheth et al., 1991), hedonic consumption (Hirschman and Holbrook, 1982; Holbrook and Hirschman, 1982), the hierarchical model of consumer goals (Ligas, 2000), and the aesthetic criteria for consumption (Friedmann, 1986) were used to judge the validity of the context of the questionnaire. In other words, when any of the results of previous studies implied the meaning of the consumption values of flowers, their framework was extracted and worded into the question statements in the questionnaire.

Dear Ladies and Gentlemen:

This survey is about the investigation of consumer behavior in the floral market. Your responses will be recorded anonymously and will be used for academic purpose only. Please feel free of privacy concerns when answering the questionnaires. Your participation is appreciated very much.

A. Please indicate your socio-economics group with a " $\sqrt{ } "$ mark in the appropriate $\square$.

1. Gender: $\square$ male, $\square$ female

2. Age: $\square 18-25$ years old, $\square 26-35$ years old, $\square 36-45$ years old, $\square$ 46-55 years old, $\square 56-65$ years old, $\square$ over 65 years old

3. Education level: $\square$ primary school, $\square$ junior high school, $\square$ senior high school, $\square$ college or university, $\square$ graduate school

4. Jobs: $\square$ civil servant, military service and education, $\square$ agriculture, forestry, fishing and animal husbandry workers, $\square$ manufacturing, $\square$ commercial business, $\square$ self-employed, $\square$ service industry, $\square$ housekeeping, $\square$ students, $\square$ others

5. Average monthly income: $\square$ under NT $\$ 20,000, \square$ NT\$20,001- NT\$40,000, $\square$ NT\$40,001NT\$60,000, $\square$ NT\$60,001 - NT\$80,000, $\square$ NT\$80,001- NT\$100,000, $\square$ over NT\$100,000

B. Please indicate the degree of your agreement regarding the statements of following items with a " $\sqrt{ }$ " mark in the appropriate $\square$.

Fig. 1. The questionnaire used to examine the differences in floral consumption values of consumers surveyed in Taiwan between 19 May and 15 June 2006 (NT\$ = New Taiwanese dollars). (Continued on next page) 


1. The price of flowers is reasonable. ................
2. The quality of flowers is good. ...................
3. The longevity of flowers is good. ...............
4. Different flowers are associated with different social language.

5. People usually have good imagination with flowers.

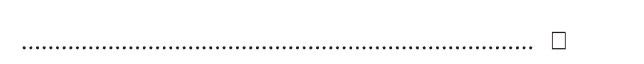

6. Flowers can be used to represent romance..... $\square$

7. Flowers can be used to indicate the best wishes for someone.

8. Flowers can be used to create the atmosphere of holidays.

9. Flowers can be presented at special occasions to show sincerity.

9.

10. Flowers can be used to represent blessing or convey wishes to friends on occasions of

celebration or sorrow.

$\square \quad \square \quad \square \quad \square$

11. Flowers can be used to represent best wishes when visiting someone who is hospitalized.

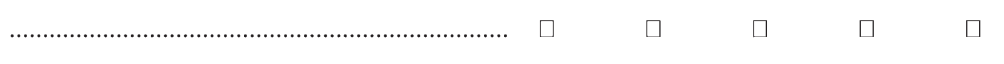

12. Flowers can be used to decorate a housing environment.

13. Flowers are represented to indicate my sincerity at the occasion of religion worship.

14. I enjoy in taking care of flowers.

$\begin{array}{llll}\square & \square & \square & \square \\ \square & \square & \square & \square\end{array}$

(Figure 1 Continued)

questionnaire's statements using a five-point Likert scale ( 5 = extremely agree, 4 = agree, $3=$ neutral, $2=$ disagree, 1 = extremely disagree). Socioeconomic data in relation to the participants, including age, gender, income, education, and occupation, were also collected using a category scale.

SAMPLING. Participants were sampled from the main cities of Taiwan, including Taipei, Taichung, and Kaohsiung, as well as the counties around Taipei, Taichung, and Kaohsiung, (i.e., Taipei, Taoyuan, Changhwa, Nantou, Chiayi, and Tainan counties). The participants were sampled from the volunteers found at the public sites, such as in the department stores, train stations, science parks, markets, campuses, post offices, and gas stations of the urban cities or rural counties described above.

The survey was conducted between 19 May and 15 June 2006. Participants were first informed with a consent letter stating the purpose of the survey, and security was guaranteed that their responses would be used for academic purposes only. Most of the participants took $\approx 10$ to 15 min to complete the questionnaire. A total of 677 consumers participated in this study. After excluding 33 incomplete questionnaires and 29 questionnaires that had incongruent responses in that the user status indicated the individuals concerned were nonusers of flowers but the purchase frequency did not have a value of zero, a total of 615 questionnaires were able to be used in the statistical analysis.

Statistical analysis. The data were analyzed using factor analysis to extract the main factors underlying the consumption value that consumers attached to the floral products. Each value factor generated was then named and illustrated according to the structure of its component variables. As a result, five consumption values were extracted for the consumption of floral products, including sensory hedonics, emotion conditioning, curiosity fulfillment, monetary worth, and showing care to others (Yeh and Huang, 2009). According to the statistical results of factor analysis, a composite measure was used as a replacement variable for each of these five floral consumption values. In other words, participants' responses to these extracted value factors were recorded with summated scales so that the average scores of the component variables for any of the extracted value factors were used as measures of the participants' perception of the values attached to the consumption of flowers in the subsequent statistical analysis (Hair et al., 1998). After this, the statistical analysis of $t$ test was used to examine the differences in the floral consumption values between the users and nonusers of flowers, while the analysis of variance (ANOVA) was applied to examine the differences among the light users, medium users, and heavy users of flowers, as well as among the consumer groups who preferred to purchase different types of flowers. Once the difference was detected as significant with ANOVA, Duncan's post hoc analysis followed to compare the differences among the consumer groups. In addition, discriminant analysis was applied to investigate the main differences across the consumer groups in regard to their consumption values for flowers. All statistical analyses were processed using SPSS (version 15.0; SPSS, Chicago).

\section{Results}

Portrait of samples. Among the 615 participants who provided valid questionnaires for statistical 
15. Flowers make me feel happy.

16. Flowers give me a feeling of joy.

17. Flowers give me a feeling of peace.

18. I have a greater intention to purchase new or special flowers.

19. Unique flowers always attract my interest. ... $\square$

20. I am interested in buying the flowers that I have never seen before.

21. I like to go to a flower market or the high-way gardening park for browsing flowers.

22. I like to have information about flowers from newspapers, magazines, Internet, flower

shows, or other media

23. I enjoy learning something about flowers from someone else.

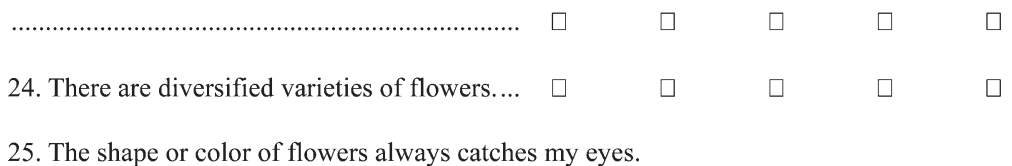

26. The smell of flowers attracts my olfactory sensation.

27. I like to touch flowers and feel satisfied with the touch.

28. I enjoy food with flowers in the recipe. .....
29. The smell of flowers makes me feel good...
30. The appearances of flowers fill me with a sense of beauty

(Figure 1 Continued)

analysis, $63.4 \%$ of the participants were female and $36.6 \%$ were male. The age distribution was: $17.6 \% 18$ to 25 years old, $42 \% 26$ to 35 years old, $20.5 \% 36$ to 45 years old, $16.4 \% 46$ to 55 years old, $3.1 \% 56$ to 65 years old, and $0.3 \%$ over 65 years. About $0.2 \%$ of the participants did not provide any age information.

The distribution of highest educational levels was: $11.1 \%$ graduate school, $63.3 \%$ college or university undergraduate, $\quad 19.0 \%$ senior-high school, 3.3\% junior-high school, and $3.1 \%$ elementary school.

Participants' occupations were as follows: $26.8 \%$ service industry; $19.5 \%$ civil servant, military service, and education; 19.0\% commercial business;
8.8\% manufacturing; $8.0 \%$ students; $5.5 \%$ housekeeping; $4.4 \%$ selfemployed; 1.1\% agriculture, forestry, fishing, and animal husbandry; and $6.5 \%$ others. A total of $0.3 \%$ of the participants did not indicate any occupation.

About $16.6 \%$ of the participants reported that they had a monthly income of less than 20,000 New Taiwanese dollars (NT\$); 50.2\% had an income between NT\$20,000 and NT\$40,000; 21.3\% between NT\$40,001 and NT\$60,000; 7.6\% between NT\$60,001 and NT\$80,000; $2.6 \%$ between NT\$80,001 and NT\$100,000; and $1.0 \%$ reported that they had a monthly income of over NT\$100,000. About $0.7 \%$ of the participants did not provide any income information.

Compared with census data, the composition of the samples skewed to the population of females, 26 to 45 years old, as well as the higher educated. However, several evidences show that the samples are valid for the investigation of consumer behavior in the floral market. For example, the statistical report from the Society of American Florists indicates that females comprise three-quarters of the consumers of floral products (Society of American Florists, 2008). Meanwhile, several previous studies reveal that participants for the study of consumer behavior in the floral market tend to be those who have higher educational levels and are aged from their 20 s to 50 s (Imanishi et al., 1992; Moore et al., 2000; Phillips et al., 2007; Posadas et al., 2006).

The Differences BetWeEN USERS AND NONUSERS. Participants were divided into two categories, namely, "users" and "nonusers" of flowers, according to their response to the questionnaire item that asked the participants whether they purchased flowers. The participants who indicated that they purchased flowers were identified as the users of flowers. By contrast, the participants who indicated that they did not purchase flowers were identified as the nonusers of flowers. A total of 492 participants were identified as users of flowers, and 123 participants were identified as nonusers of flowers.

The group means indicated that users and nonusers of flowers had similar views regarding the consumption values of the flowers in that both groups had strongest perception to the social value of showing care to others, followed by the psychological value of emotion conditioning, and then the experiential value of sensory hedonics. However, the statistical results of $t$ test indicated that the consumer groups differed significantly from each other regarding their perception strength for all the floral consumption values, except for the value of showing care to others $(\alpha=0.05)$. In particular, these two groups revealed the greatest difference in relation to the value of curiosity fulfillment (with a discriminant loading of 0.861 ), followed by the values of emotion conditioning (with 
31. Flowers always provide me with visual enjoyment.

32. Flowers always provide me with olfactory enjoyment.

33. Touching flowers can lift up my spirit.

C. Please indicate your responses for the following questions with a " $\sqrt{ }$ " mark in the

appropriate $\square$, or write your answers in the blank space.

1. Do you buy flowers? $\square$ Yes, $\square$ No

2. Averagely how many times per year do you buy flowers? times/year

3. What kind of floral products do you buy most of the time? (single choice)

$\square$ cut flowers
$\square$ potted plants
$\square$ bedding plants
$\square$ bulbs
$\square$ seeds
$\square$ others

(Figure 1 Continued)

discriminant loading of 0.714$)$, and sensory hedonics (with a discriminant loading of 0.586), according to the statistical results of the discriminant analysis (Box's $\mathrm{M}=8.85, P=0.892$; Wilks' $\lambda=0.90, \chi^{2}=64.76, P=$ $0.000)$. Relevant statistical results are presented in Table 1. Generally speaking, the users of flowers had a stronger perception toward these values than the nonusers of flowers. It is obvious that psychologically and hedonically, the users of flowers are more sensitive to flowers, and their enjoyment of and demand for a variety of floral products are much greater than those of the nonusers of flowers (Table 1).

From a theoretical point of view, one kind of product may be associated with multiple values for consumers. For example, Sweeney and Soutar (2001) suggested that emotional value, social value, quality/performance, and price/value for money are the general consumption values for durable goods. Hirschman and Holbrook (1982)

Table 1. Summary of $t$ test and discriminant analysis applied to examine the differences in floral consumption values between the users and nonusers of flowers based on 615 valid questionnaires surveyed in Taiwan between 19 May and 15 June 2006.

\begin{tabular}{|c|c|c|c|c|c|}
\hline \multirow{3}{*}{$\begin{array}{l}\text { Consumption } \\
\text { values }\end{array}$} & \multicolumn{2}{|c|}{ Group means ${ }^{\mathrm{z}}$} & \multirow{2}{*}{\multicolumn{2}{|c|}{$\begin{array}{c}t \text { test for } \\
\text { equality of } \\
\text { group means } \\
\end{array}$}} & \multirow{3}{*}{$\begin{array}{c}\text { Discriminant } \\
\text { loadings }\end{array}$} \\
\hline & \multirow{2}{*}{$\begin{array}{c}\text { Users } \\
(\mathrm{n}=492)\end{array}$} & \multirow{2}{*}{$\begin{array}{l}\text { Nonusers } \\
(\mathrm{n}=123)\end{array}$} & & & \\
\hline & & & $t$ & $P$ & \\
\hline Sensory hedonics & 3.42 & 3.10 & 4.85 & 0.000 & 0.586 \\
\hline Emotion conditioning & 3.92 & 3.57 & 5.92 & 0.000 & 0.714 \\
\hline Curiosity fulfillment & 3.38 & 2.87 & 7.13 & 0.000 & 0.861 \\
\hline Monetary worth & 3.17 & 3.01 & 2.38 & 0.018 & 0.287 \\
\hline Showing care to others & 4.06 & 4.02 & 0.58 & 0.564 & 0.070 \\
\hline
\end{tabular}

${ }^{\mathrm{z}}$ Measured with the average score of the component variables. proposed the experiential value of multisensory perception to indicate that for some purchases, consumers consume certain products simply because of the beauty of the products or for the sensory hedonics stimulated by the products. Consumption values are sometimes generated by possessing or using the product, such as the symbolic value of self-identification and self-extension via possessing or using that product (Ligas, 2000). Sheth et al. (1991) concluded that there are five consumption values for consumers to make a purchase choice, i.e., functional value, social value, emotional value, epistemic value, and conditional value. Obviously, most of the values described above are associated with the consumption of flowers, too, except that the epistemic value (e.g., curiosity fulfillment) was not obvious for the nonusers of flowers. The group means of the curiosity fulfillment for the nonusers was even below the neutral point (Table 1).

THE DifFerences AMONG THE LIGHT USERS, MEDIUM USERS, AND HEAVY USERS. To further investigate the differences in floral consumption values among the users who purchase flowers at different frequencies, the 492 users of flowers were classified into three groups: light users, medium users, and heavy users of flowers. Light users were participants who claimed that, on average, they made one to two purchases of flowers annually; medium users were those who claimed they made three to five purchases of flowers annually; and heavy users were those who claimed they made six or more purchases annually. As a result, 182 participants $(37 \%)$ were identified as light users of flowers, $173(35 \%)$ as medium users, and $137(28 \%)$ as heavy users.

The group means showed that the light users and medium users had similar perception patterns in that they both had the strongest perception of the social value of showing care to others, followed by the values of emotion conditioning, sensory hedonics, curiosity fulfillment, and monetary worth in regard to their floral consumption values. However, the heavy users revealed a different perception pattern from these two consumer groups in that the heavy users had the strongest perception of the psychological value of emotion 
conditioning instead of the social value of showing care to others. The heavy users' perception of the value of curiosity fulfillment was also stronger than that of sensory hedonics, which contrasted with the perceptions of the light users and medium users.

Examined univariately, the statistical results of ANOVA and Duncan's post hoc analysis indicated that the light users, medium users, and heavy users differed significantly in terms of the floral consumption values of sensory hedonics, emotion conditioning, curiosity fulfillment, and monetary worth $(\alpha=0.05)$. In general, the participants who purchased flowers more frequently revealed stronger perceptions to these values (Table 2 ).

When discriminant analysis was applied to examine the main differences in the floral consumption values among the light users, medium users, and heavy users (Box's $M=50.66$, $P=0.013$ ), a discriminant model with two discriminant functions (Wilks' $\left.\lambda=0.88, \chi^{2}=62.17, P=0.000\right)$ was generated due to there being three comparison categories for the dependent variable (i.e., light users, medium users, and heavy users). To evaluate the total contribution of each value variable across the discriminant functions for the model as a whole, a potency index was calculated for each value variable. The potency index is a composite measure of the discriminatory power of an independent variable across all the discriminant functions when more than one discriminant function is estimated. Relatively speaking, the greater the potency index, the stronger the discriminatory power with which an independent variable is associated
(Hair et al., 1998). As a result, the potency index indicated that the light users, medium users, and heavy users of flowers mainly differed in terms of the value variables of curiosity fulfillment, emotion conditioning, and sensory hedonics in regard to their floral consumption values. In particular, curiosity fulfillment had the greatest discriminatory power in terms of the differentiation of these consumer groups (Table 2).

Fundamentally, the heavy users had a different perception pattern for the consumption values of flowers when compared with the light users and medium users. The heavy users revealed the characteristics that the psychological value (i.e., emotional conditioning) was stronger than the social value (i.e., showing care to others), and that the epistemic value (i.e., curiosity satisfaction) was stronger than the sensory hedonics, with the reverse situation applying to the light users and medium users. Such a finding is consistent with de Boon's view that in a highly developed floral market, flowers are sold on the basis of emotion. Therefore, how to stimulate the consumers' emotion and turn that emotion into purchases of flowers needs to be a major priority in attempts to sell more flowers (de Boon, 1990).

THE DIFFERENCES FOR THE USERS OF CUT FLOWERS, POTTED PLANTS, AND OTHER TYPES OF FLORAL PRODUCTS. While cut flowers, potted plants, and bedding plants are important types of floral products in the floriculture industry, whether consumers behave differently in regard to the purchases of these different types of floral products is rarely investigated in the literature. This section is intended to address this deficiency.

The 492 users of flowers in this study were classified into three categories according to their most preferred product type; 209 of the users of flowers claimed that they preferred to purchase cut flowers, while 108 claimed that they preferred to purchase potted plants, and 167 preferred to purchase other kinds of floral products, such as bedding plants, bulbs, or other items. Eight participants among the users of flowers did not indicate their preferred product type, and thus the data for these eight participants were not used in the statistical analysis in this section.

The group means showed that the participants who preferred to purchase cut flowers had similar perception patterns in regard to floral consumption values to those who preferred to purchase bedding plants, bulbs, or other items. They had the strongest perception of the social value of showing care to others, which was then followed by the values of emotion conditioning, sensory hedonics, curiosity fulfillment, and last, monetary worth. These findings were slightly different from those of the participants who preferred to buy potted plants. For the participants who preferred potted plants, the perception of the value of curiosity fulfillment was a little stronger than in relation to sensory hedonics (Table 3 ).

The statistical results of ANOVA and Duncan's post hoc analysis indicated that the participants who preferred different types of floral products differed significantly in terms of the consumption values of

Table 2. Summary of ANOVA and discriminant analysis performed to examine the differences in floral consumption values for the light users, medium users, and heavy users of flowers $(1-2,3-5$, and $\geq 6$ purchases per year, respectively) based on 492 valid questionnaires surveyed in Taiwan between 19 May and 15 June 2006.

\begin{tabular}{|c|c|c|c|c|c|c|c|c|}
\hline \multirow{3}{*}{$\begin{array}{l}\text { Consumption } \\
\text { values }\end{array}$} & \multirow{2}{*}{\multicolumn{3}{|c|}{ Group means $\mathrm{s}^{\mathrm{z}}$}} & \multirow{3}{*}{\multicolumn{2}{|c|}{$\begin{array}{l}\text { ANOVA for } \\
\text { equality of } \\
\text { group means }\end{array}$}} & \multicolumn{3}{|c|}{ Discriminant analysis } \\
\hline & & & & & & \multicolumn{2}{|c|}{$\begin{array}{l}\text { Discriminant } \\
\text { loadings }\end{array}$} & \multirow{2}{*}{$\begin{array}{l}\text { Potency } \\
\text { index }\end{array}$} \\
\hline & $\begin{array}{l}\text { Light users } \\
(\mathrm{n}=182)\end{array}$ & $\begin{array}{c}\text { Medium users } \\
(\mathrm{n}=173)\end{array}$ & $\begin{array}{l}\text { Heavy users } \\
(\mathrm{n}=1 \mathbf{1 3 7})\end{array}$ & & & Function & Function & \\
\hline Sensory hedonics & $3.29 \mathrm{a}^{\mathrm{y}}$ & $3.40 \mathrm{a}$ & $3.63 \mathrm{~b}$ & 10.39 & 0.000 & 0.589 & -0.044 & 0.316 \\
\hline Emotion conditioning & $3.78 \mathrm{a}$ & $3.93 \mathrm{~b}$ & $4.10 \mathrm{c}$ & 11.57 & 0.000 & 0.613 & 0.332 & 0.352 \\
\hline Curiosity fulfillment & $3.17 \mathrm{a}$ & $3.36 \mathrm{~b}$ & $3.68 \mathrm{c}$ & 21.50 & 0.000 & 0.847 & 0.091 & 0.654 \\
\hline Monetary worth & $3.05 \mathrm{a}$ & $3.19 \mathrm{ab}$ & $3.28 \mathrm{~b}$ & 5.28 & 0.005 & 0.401 & 0.398 & 0.161 \\
\hline Showing care to others & $4.01 \mathrm{a}$ & $4.14 \mathrm{a}$ & $4.03 \mathrm{a}$ & 2.14 & 0.118 & 0.000 & 0.850 & 0.065 \\
\hline
\end{tabular}

${ }^{2}$ Measured with the average score of the component variables.

'Means with the same letter are equal at $\alpha=0.05$ according to the statistical results of Duncan's post hoc analysis 
Table 3. Summary of ANOVA and discriminant analysis performed to examine the differences in floral consumption values for the purchasers of different types of flowers based on 484 valid questionnaires surveyed in Taiwan between 19 May and 15 June 2006.

\begin{tabular}{|c|c|c|c|c|c|c|c|c|}
\hline \multirow{2}{*}{$\begin{array}{l}\text { Consumption } \\
\text { values }\end{array}$} & \multicolumn{3}{|c|}{ Group means ${ }^{\mathrm{z}}$} & \multirow{2}{*}{\multicolumn{2}{|c|}{$\begin{array}{l}\text { ANOVA } \\
\text { for equality } \\
\text { of group } \\
\text { means } \\
\end{array}$}} & \multicolumn{3}{|c|}{ Discriminant analysis } \\
\hline & $\begin{array}{l}\text { Cut flowers } \\
(\mathrm{n}=209)\end{array}$ & $\begin{array}{l}\text { Potted plants } \\
\quad(\mathrm{n}=108)\end{array}$ & $\begin{array}{c}\text { Bedding } \\
\text { plants, bulbs, } \\
\text { and other } \\
\text { items }(\mathrm{n}=167)\end{array}$ & & & $\begin{array}{c}\text { Function } \\
1\end{array}$ & $\begin{array}{c}\text { Function } \\
2 \\
\end{array}$ & $\begin{array}{c}\text { Potency } \\
\text { index }\end{array}$ \\
\hline Sensory hedonics & $3.38 \mathrm{a}^{\mathrm{y}}$ & $3.35 \mathrm{a}$ & $3.55 \mathrm{~b}$ & 4.31 & 0.014 & 0.471 & 0.812 & 0.337 \\
\hline Emotion conditioning & $3.91 \mathrm{a}$ & $3.92 \mathrm{a}$ & $3.95 \mathrm{a}$ & 0.18 & 0.839 & 0.128 & 0.077 & 0.014 \\
\hline Showing care to others & $4.08 \mathrm{a}$ & $4.01 \mathrm{a}$ & $4.07 \mathrm{a}$ & 0.48 & 0.622 & -0.112 & 0.325 & 0.037 \\
\hline
\end{tabular}

${ }^{\mathrm{z}}$ Measured with the average score of the component variables.

'Means with the same letter are equal at $\alpha=0.05$ according to the statistical results of Duncan's post hoc analysis.

sensory hedonics and curiosity fulfillment in regard to the purchases of flowers. The participants who preferred cut flowers had almost the weakest perception for each of these two values. By contrast, the participants who preferred bedding plants, bulbs, or other kind of floral products, except in the case of the potted plants, had the strongest recognition of these two values. For the participants who preferred potted plants, the perception of the value of curiosity fulfillment was about equal to that for the participants who preferred bedding plants, bulbs, or other items, and their recognition of the value of sensory hedonics was about equal to that of the participants who preferred cut flowers. The potency index based on the discriminant analysis (Box's $\mathrm{M}=43.88, P=0.057$; Wilks' $\lambda=0.95, \chi^{2}=25.07, P=0.005$ ) indicated that the greatest difference among the consumers who preferred different types of floral products was centered on the value of curiosity fulfillment, with regard to their floral consumption values (Table 3 ).

\section{Discussion}

The results of this study indicate that the consumer groups who made different purchase choices in relation to the floral products possessed different floral consumption values. However, their perceptions of the flowers' social value, as in presenting flowers to show care to others, were very common and consistent, regardless of what their choice was for the purchases of flowers. Flowers have been associated with various social meanings across different human cultures since ancient times (Goody, 1993). Even in contemporary times, human beings use flowers for various social reasons, for instance, in presenting flowers as gifts for social reasons or for religious worship (Criley, 2008; Goody, 1993; Libbon, 2000; Oppenheim, 1996; Waldrop, 1992). Obviously, the social value of flowers has become deeply rooted into the minds of human beings, and has been an integral part of human life for so many generations and across different human cultures. Therefore, it is reasonable to see that the floral consumption value of "showing care to others" has been strongly perceived by various consumer groups in this study. Even the heavy users of flowers have placed a stronger emphasis on the psychological value of emotion conditioning in regard to the floral products, their perception of the social value of flowers (i.e., showing care to others) has been strong. This is consistent with the previous finding that gift giving is an important intended use that forces consumers to consume more flowers (Huang, 2005).

Although curiosity fulfillment, which refers to the value of satisfying the consumers' need to seek variety in relation to floral products, was not the strongest value that the consumers held regarding the consumption of flowers, the greatest differences across the consumer groups who exhibited different choice behavior in regard to the floral products were located in this variable. Such differences are very likely to serve as an intrinsic driving force for the consumers to behave differently in terms of information search, product trial and choice switching in the floral market. Theoretically, variety seeking is one of the components of consumers' novelty seeking behavior. According to Hirschman's (1980) hypothesis, the action of novelty seeking consists of two types of behavior, namely, seeking new information and variety seeking. Searching for new information is an exploratory form of behavior related to new information, and helps consumers accumulate potentially useful information to improve problem-solving skills, while variety seeking is relevant to alternating choices among known stimuli. Consumers seek product variety to reduce boredom or tiredness. Because new products may constitute new information in the form of ideas, services, and tangible goods, when a consumer expresses a willingness to adopt a new product, it is necessary for him/her to express a desire for novel information to accumulate useful knowledge to improve his/her judgment of the alternatives, or to improve the performance of newly adopted products (Hirschman, 1980). Basically, both actions of variety seeking and information search are highly correlated. In an empirical study, Dodd et al. (1996) studied the relationships of variety seeking and information search behavior for wine enthusiasts, and found that the enthusiasts who revealed higher tendency to seek product variety usually use a greater number of information sources.

Accordingly, because the consumer groups that exhibit different choice behavior in relation to the purchases of flowers possess the great differences in terms of the value of curiosity fulfillment, such differences may lead the consumers to behave differently in their search for information with regard to floral products. The consumers who have a lower 
curiosity fulfillment value for flowers, such as the nonusers and light users of flowers, have less of a tendency to search for the product variety with regard to the purchases of flowers, and therefore they are less likely to be involved in searching for product information regarding flowers. Meanwhile, a consumer's perception of external information is a selective mechanism (i.e., consumers only access the commercial information that they are interested in having or are motivated to have). If the information is not interesting or is not needed, consumers see it as noise and develop avoidance strategies, such as zip past or zap out strategies, to avoid it (Cronin and Menelly, 1992). These theoretical rationales and the findings of this study imply that it is difficult to communicate with the nonusers and the light users of flowers regarding product information because they are neither interested in, nor sufficiently motivated to, desire information regarding flowers. These phenomena are crucial for the effectiveness of commercial communications launched by florists. That is, attributes for an effective communication with the nonusers and the light users of flowers need to be investigated to increase the success of the market penetration work to sell more flowers.

\section{Conclusion}

This study explores the characteristics of consumers' floral consumption values across the consumer groups that have different purchase choices regarding flowers. Answers as to why some consumers purchase more flowers and what consumers want from the products they buy become clear.

Generally speaking, the floral consumption values investigated were commonly recognized by the consumers, but the consumer's perception of the floral consumption values varies with consumers' status in terms of purchase frequency and the product type preferred. Basically, the nonusers of flowers do not exhibit the value of curiosity fulfillment in regard to flowers. In contrast, among the users of flowers, consumers who have higher floral purchase frequencies reveal a stronger recognition for the value of curiosity fulfillment for flowers. In addition, the heavy users reveal different perception patterns from the light users and medium users in that the heavy users exhibit the characteristic of the psychological value going beyond the social value in relation to flowers. Such characteristics imply that the heavy users consume more flowers partly due to their being emotionally more approachable for being stimulated by flowers. Furthermore, the higher perception of the value of curiosity fulfillment will lead the heavy users to have a stronger tendency to seek product variety and to enjoy more of the novelty and variety when purchasing flowers.

Consumers who prefer to buy different types of flowers also reveal some differences in terms of their floral consumption values. The main differences in the floral consumption values of these consumer groups are located in the sensory hedonics and curiosity fulfillment variables. Consumers who prefer to buy potted plants, bedding plants, bulbs, etc. have higher degrees of perception of the value of curiosity fulfillment in relation to the purchases of flowers. These consumers are expected to have a higher tendency to search for the product varieties when purchasing flowers. Because the consumers who prefer to buy bedding plants, bulbs, or other items, apart from cut flowers and potted plants, also reveal a higher degree of perception in regard to the sensory hedonics of flowers, their demand for the experience of sensory joy is also expected to be stronger in regard to their purchases of flowers.

In summary, the main differences in floral consumption values for consumer groups that make different purchase choices of flowers were found in the value of curiosity fulfillment. The phenomenon implies that there should be a great difference among these consumer groups regarding the tendency to seek product variety and information from the floral market. The nonusers and light users of flowers, or the consumers who prefer to buy cut flowers, have lower degrees of curiosity fulfillment value regarding the consumption of flowers, and so they should be less likely to seek product variety when purchasing flowers. As a consequence, they are potentially more likely to keep away from the commercial information advertised by the florists.

The outcome of this study helps the florists to work better at creating different product values for different floral products, as well as for different persons, to satisfy consumers' demands more effectively. Dissatisfied experience in the purchases of flowers impacts the consumer's intention to purchase flowers, which is likely to cause the consumers to switch their purchase choice for flowers. Because values switch generation by generation, to avoid the occurrence of customer dissatisfaction, the floral consumption values need to be traced generation by generation to satisfy the consumer's demand and preferences more precisely and consequently to retain the customer's loyalty. The results of this study also reveal the challenges of marketing communications with the nonusers and the light users of flowers. Due to the inner lack of curiosity about flowers, the task of transforming the nonusers and light users of flowers into the users and heavy users of flowers, respectively, becomes very challenging for the practitioners in the floral market.

\section{Literature cited}

Behe, B.K. and D.J. Wolnick. 1991. Market segmentation of Pennsylvania floral consumers by purchase volume and primary retail outlet. HortScience 26:1328-1331.

Criley, R.A. 2008. Ornamentals: More than just beautiful. Acta Hort. 788:23-28.

Cronin, J.J. and N.E. Menelly. 1992. Discriminating vs. avoidance: "Zipping" of television commercials. J. Advertising 21:1-7.

de Boon, I.H. 1990. A world perspective on more flowers for more people. Professional Plant Growers Assn. News 21:7, 10-11.

Dodd, T.H., B.E. Pinkleton, and A.W. Gustafson. 1996. External information sources of product enthusiasts: Differences between variety seekers, variety neutrals, and variety avoiders. Psychology Mktg. 13:291-304

Friedmann, R. 1986. Psychological meaning of products: Identification and marketing applications. Psychology Mktg. 3:1-15.

Goody, J. 1993. The culture of flowers. Woolnough Bookbinding, Irthlingborough, England.

Hair, J.F., Jr., R.E. Anderson, R.L. Tatham, and W.C. Black. 1998. Multivariate data analysis. 5th Intl. ed. PrenticeHall, Upper Saddle River, NJ. 
Hirschman, E.C. 1980. Innovativeness, novelty seeking, and consumer creativity. J. Consum. Res. 7:283-295.

Hirschman, E.C. and M.B. Holbrook. 1982. Hedonic consumption: Emerging concepts, methods and propositions. J. Mktg. 46:92-101.

Holbrook, M.B. and E.C. Hirschman. 1982. The experiential aspects of consumption: Consumer fantasies, feelings, and fun. J. Consum. Res. 9:132-140.

Huang, L. 2005. Floral product behaviors and their influence on consumer floral purchase frequency. HortTechnology 15:766-771.

Imanishi, H., F. Yonezawa, and H. Imanishi. 1992. Psychological research on the attitudes of florist customers towards flowers. J. Jpn. Soc. Hort. Sci. 60:981-987.

Jowkar, M.M., Z. Farshadfar, and A.R. Rahmaniyan. 2007. Predicting cut flower consumers' taste and preference for consumers' preference based selection in Shiraz, I.R. Iran. Acta Hort. 747:75-80.

Kim, H.H., Y.J. Kyung, K. Ohkawa, C.H. Pak, and B.H. Kwack. 1999. Flower industry in Korea. Acta Hort. 482:407-414.
Libbon, R.P. 2000. Dear data dog: What does my mother expect for Mother's Day? Amer. Demogr. 22:25.

Ligas, M. 2000. People, products and pursuits: Exploring the relationship between consumer goals and product meanings. Psychology Mktg. 17:9831003.

Matsuo, E. 2008. Humanity in horticulture: Healing and pleasure. Acta Hort. 790:39-44.

Moore, E.H., B.K. Behe, and A. Cameron. 2000. Consumer perceptions of selected flower plants. Acta Hort. 536:521-528.

Oppenheim, P.P. 1996. Understanding the factors influencing consumer choice of cut flowers: A means-end approach. Proc. XIII Intl. Symp. Hort. Econ., New Brunswick, NJ.

Oppenheim, P.P. 2000. Segmentation and target marketing in a floral market. Acta Hort. 536:529-536.

Phillips, J., E.J. Holcomb, and K. Kelley. 2007. Determining interest in valueadded planters: Consumer preference and current growers and retailer perceptions. HortTechnology 17:238-246.

Posadas, B.C., C.H. Coker, G. Fain, and P.R. Knight. 2006. Consumer survey of selected garden chrysanthemum cultivars in Mississippi. HortTechnology 16:539543.

Sheth, J.N., B.I. Newman, and B.L. Gross. 1991. Why we buy what we buy: A theory of consumption values. J. Bus. Res. 22:159-170.

Society of American Florists. 2008. The changing floriculture industry. 4th ed. Soc. Amer. Florists, Alexandria, VA.

Sweeney, J.C. and G.N. Soutar. 2001. Consumer perceived value: The development of a multiple item scale. J. Retailing 77:203-220.

Waldrop, J. 1992. Romantic gestures. Amer. Demogr. 14:4.

Yeh, T. and L. Huang. 2009. An analysis of floral consumption values and their difference for genders and geographic regions. HortTechnology 19:101-107. 